\title{
A framework for online social networking features
}

\author{
Mohsen Shafiei Nikabadi and Fatemeh Maleki*
}

Department of Economics and Management, Semnan University, Semnan, Iran

CHRONICLE ABSTRACT

Article history:

Received December 2, 2013

Accepted 8 May 2014

Available online

May 152014

Keywords:

Online social network

Social network

Websites

\section{Introduction}

Recent years, social network analysis has emerged as a distinct field of economics and it plays an essential role in many areas. Economists have been interested in networks because they believe the networks are important channels for transferring information (Mayer, 2009). Rapid growth of information technology, internet and development of E-commerce, has created substantial opportunities. Internet penetrates significantly in various characteristics of people's levies like communication, entertainments and social activities. Several businesses due to the opportunities

*Corresponding author.

E-mail addresses: f maleki72@yahoo.com (F. Maleki)

\begin{abstract}
Social networks form a basis for maintaining social contacts, finding users with common erests, creating local content and sharing information. Recently networks have created a fundamental framework for analyzing and modeling the complex systems. Users' behavior studies and evaluates the system performance and leads to better planning and implementation social networks' characteristics. In terms of objective, this survey is practical descriptive. Sampling has been done among 384 of graduate students who have good experiences of membership in online social network. Confirmatory factor analysis is used to evaluate the validity of variables in research model. Characteristics of online social networks are defined based on six components and framework's indexes are analyzed through factor analysis. The reliability is calculated separately for each dimension and since they are all above 0.7, the number of people who apply for membership in various online social networking is an important index. In terms of individual preference to connect with, people who are relative play essential role in social network development. In terms of homogeneity variable, the number of people who visit their friends' pages is important for measuring frequency variable. In terms of proximity, being in the same city is a more important index and index of creating a sense of belonging and confidence is more important for measuring reciprocity variable.
\end{abstract}


created by online business models have moved from physical retailers into the virtual market (Shiau \& Luo 2012).

Today, social media provides appropriate facilities for performing researches in the virtual environment virtually under no significant expenses. These researches help companies select their objectives and calculate the amount of return on Investment. The main purpose of social marketing is not only helps business development in early stages, but also it provides infrastructure and processes for enterprises and, finally, improves sales figures. Many experts believe that social network make potential changes in the behavior of consumers and influence widely on capacities, techniques and communications of crafts (Pallis et al., 2011).

This research offers a framework for online social network's features. Researches and model for social network features have been analyzed in social and behavior sciences. However, special model or framework, which is associated with online social network features, has not been observed. Therefore, researcher by studding previous researches and, analyzing content, and field research, provides a framework for online social networks' features. Introduction of this framework and explaining indexes of online social networks is considered as an innovation aspect.

\section{Review of literature}

\subsection{Social network}

Social network is originated to sociology and the concept of network is associated with relationships among individuals, groups of people or organization parts that creates social network. Social networks are different based on their size and heterogeneity. Larger networks are more heterogeneous and more complex and have more diverse social features. Advance of technologies and innovations change the nature of social networks. Traditional social networks consisted of personal interactions of human during the time, while today computer, which indicates an impersonal form of mediated communications, executes these interactions. These mediated computer networks, or internet social networks are more complex and more heterogeneous. Yet, the advantages of social networks in online environment, in which place and time problems are not important, are increasing. The users of online networks can share their information and provide solution to various places around the world in a very short period of time ( Michaelidou et al., 2011).

Modern technologies change gradually the social interactions among people. People, on average, give more time to make connection with the help of operating system technologies, and their connection is repeatedly available for processors of these technologies. With the advent of web2, immediate messaging and social network websites are observed anywhere and these media provide the possibility to prepare the plan of communication path among users (Katona et al., 2011).

In these sites, users present their demographic information and edit (decorate) their profiles and they connect to their friends clearly and because of this, they display their communication pattern. Operating system technologies of social interactions attract the attention of marketers who want to analyze media as an advertisement tool. In fact, income models of social networks are mainly based on advertisement (Katona et al., 2011).

Social network sites provide the possibility of services like messaging, sharing information and communication and these sites create a soft, flexible and appropriate foundation for individuals to make and maintain online friendship. In social network sites, the communication of users connected to each other is based on mutual agreement. In blogging and social network sites, users can easily connect to societies or groups who share common benefits and activities. Generally, it is possible to refer to blogging networks and social network sites as the representative of online social networks in 
the age of Web2. Furthermore, blogs and social network sites are important social media, which are new advent (Fu et al. 2008).

\subsection{Online social network sites}

Development and public popularity of Web2 applications have built a new world of cooperation and communications. More than 1 billion individuals in the world have connected to each other. Individuals protect each other's idea and message via Wikis and Podcasts. New generations of online social networks (applying of Web2), as make the publication of high-speed internet possible, in the same manner, they have formed main connections and interaction aspect with the increasing importance. Online social network sites have created online spaces in which individuals can construct personal networks by building profiles and making connection with other people. The objective of online social network sites is social interaction and connection these sites give every individual space to share their contents, pictures and videos with their friends. They also connect individuals with their friends, coworkers and classmates living around them. Online, social networks help people to be aware about events, ceremonies and other social activities. Participating and continuity in these networks show a new social phenomenon, which generally depend on the interaction with other users in personal networks (Cheung \& Lee 2010).

\subsubsection{Definition of online social network sites}

According to Boyd (2007) modern social network sites is defined as "social networks include services on the base of Web which make people 1) to create public or semipublic profile in the boundaries of the system, 2) to provide a list from other users and who they are connect with and 3) to observe and roll list of connection in the system". Similarly, Hitwise and Experian (2007) also explain that "Websites of social networks are online communication among people who share interests and activities. Websites provide different methods for the users to connect each other via conversation, message, or e-mail". Williams (2010) states that the software of online social networks is a service based on Internet, which helps users build virtual and management social networks. Miller (2007), accordingly, built an interaction networks included users' profiles, pictures, groups, emails, blogs, music, and other media. On the other hand, Mahajan (2009) refers to a society on the internet, which simplifies the users' interactions for a common goal (Din et al., 2011)

\subsection{Dimension of online social network}

Mislove et al. (2007) measured and analyzed various structures of online social network by gathering some necessary data from 4 popular online social networks: Flicker, YouTube, Live Journal and Orkut, which consist of well over 11.3 million users and 328 million links. The result of "the power of Law" confirmed the small world of online social networks and the featured of "free measure" (without measure) for online social network (Mislove et al., 2007).

Mergeland and Langenberg (2006) investigated on different factors, which could lead to the creation, maintenance, decay and reconnection of online network ties. They studied the individual, dual, and structural features and related indexes with the content of why and how of different stage of people connection in online communication. Lee et al. (2011) analyzed the friendship in online social networks in high-education institute level via space interaction models. They focused on recognizing institutional features associated with the power of communications among individuals. The results indicated that the geographical distance was the most important separation factor.

Benevenato et al. (2012) analyzed the number of users in online social networks by gathering the information thorough an online social network Web in Brazil by concentrating on the users to confirm their identity for connecting to social network. Analyzing of data gathered through clickstream indicated key features like, the amount of work in social network, how people connect to social network and the amount of time, and also kinds and sequences of activities accomplished by 
users on a site. The results indicated that friendship requests of users usually were sent to their geographical proximity. Zhao et al. (2008) provided a new framework for measuring the power of communication among different users and from various activities in online social network. Two kinds of information resources in suggestive graphic model, for estimating the power of communication among users were used including information associated with users' features and interaction activities among various users. They confirmed the possibility-measuring and effectiveness of research. The opportunity of social interactions and participation in it are determined thorough structural features of social network. Structural feature analyzed for social network in this study including size, frequency, density, proximity, homogeneity and reciprocity.

\section{Table 1}

Criteria of Online Social Networks

\begin{tabular}{ll}
\hline Factor & Reference \\
\hline Size & Ashida, 2005; Hanneman \& Riddle, 2005; Kantona (2011) \\
Frequency & Ashida. 2005 \\
Density & Ashida, 2005; Martin, 2012 \\
Proximity & Ashida, 2005; Hanneman \& Riddle, 2005 \\
Homogeneity & Ashida, 2005 \\
Reciprocity & Ashida, 2005; Shiav et al., 2005, Kantona (2011), \\
\hline
\end{tabular}

The size of social network: size of a network can refer to its links. The volume of network is the number of links which place one link with proximate link (Hanneman \& Riddle, 2005).

\section{Table 2}

Indicators of online social network size

Friendship continuous increase in online social networks

Receiving emotional support and useful communication in online social networks

Average number of friends (connections) in Online Social Networks

Membership increasing in different online social network

Homogeneity of social network: homogeneity of social network is another feature which explains the whole network according to individual's connections in network. Homogeneity explains members' demographic similarity. Literature suggests that emotional and useful protect in homogenous network is more than network with less homogenous rate (Glass et al. 1999).

\section{Table 3}

Homogenous indexes of online social networks

Individual preference (groups or organization) to be in the same gender when connect to each other

Individual preference to be in the same age when connect to each other

Individual preference to be in the same university when connect to each other

Individual preference to be relative when connect to each other

\section{Frequency of connection among network links}

Frequency (frequency of occurrence) of social networks is determined by receiving information about the number of times a person can communicate with a social tie. Although one analyses indicate that frequency, compared with the quality of interaction in a social network, is not so important. It seems that the frequency of connection in social networks related to the availability, adequacy of social protect and to the accompaniment and companionship (Ashida, 2005).

\section{Table 4}

Frequency indexes of online social network

Elapsed time of the day in online social networks

The number of connection in online social network in a week

Time spent on online social network in each connection to internet

Visiting friend pages(groups or organizations) in each connection to online social network

Visiting non-close friends pages (groups or organizations) in each connection to online social network 


\section{Density of social network}

Density is defined as "to what extent the members of network connect to each other permanently". It is possible that if individuals in social network connect each other, permanently, the emotional and evaluation support level in identified social network will increase. Density is a parameter, which represents the ratio of the number of ties in a network divided by the total number of possible relationships between the constituent members of Net (Martins et al., 2012). Similarly, if individuals get close to social links, their tendency to other members of network will increase (Ashida, 2005).

\section{Table 4}

Density indexes of online social network

The use of entertainment and recreation services in online social networks

The use of dialogue and participation in online social networks

The use of information and experience sharing in online social networks

Communicate with people in online social networks who are associated with them in the real world

\section{Proximity of network links}

The proximity of network links can be described as geographical distances among network members (Ashida, 2005). Average of this distance is the shortest drawn line between two points among all connected pairs in network in which every individuals is in direct connection with other members (Hanneman \& Riddle, 2005).

\section{Table 5}

Proximity indexes of online social network links

Geographical distance of online social network members

Being in the same country in online social networks

Being in the same city in online social networks

\section{Reciprocity in network communications}

Reciprocity is defined as "How much resources and support given and received in a relationship. Reciprocity is considered as an effective aspect and good function in social communication (Ashida, 2005). Reciprocity is often interpreted as a compensating behavior. This concept is on the basis of the kind of social exchange via individual behavior. Information systems define reciprocal relationship as a main belief, which is the result of sharing knowledge. Reciprocity and trust are two important factors, which result in sharing knowledge. Reciprocal relationship is the most important influential factor to share knowledge in society and it impacts the quality of a special behavior. Reciprocal relationships are defined as the degree of individual's belief whether they can receive reciprocal benefits thorough sharing knowledge (Shiau \& Luo, 2012).

\section{Table 6}

Reciprocity indexes in online social network

Create a sense of belonging and confidence in individuals, groups or organizations who are members of online social networks

To be reciprocal protect and support in an online relationship in online social network relationships.

\section{Research methodology}

\subsection{Conceptual model}

With respect of reviewing literature, now it is possible to draw the conceptual model for research as the following model, 


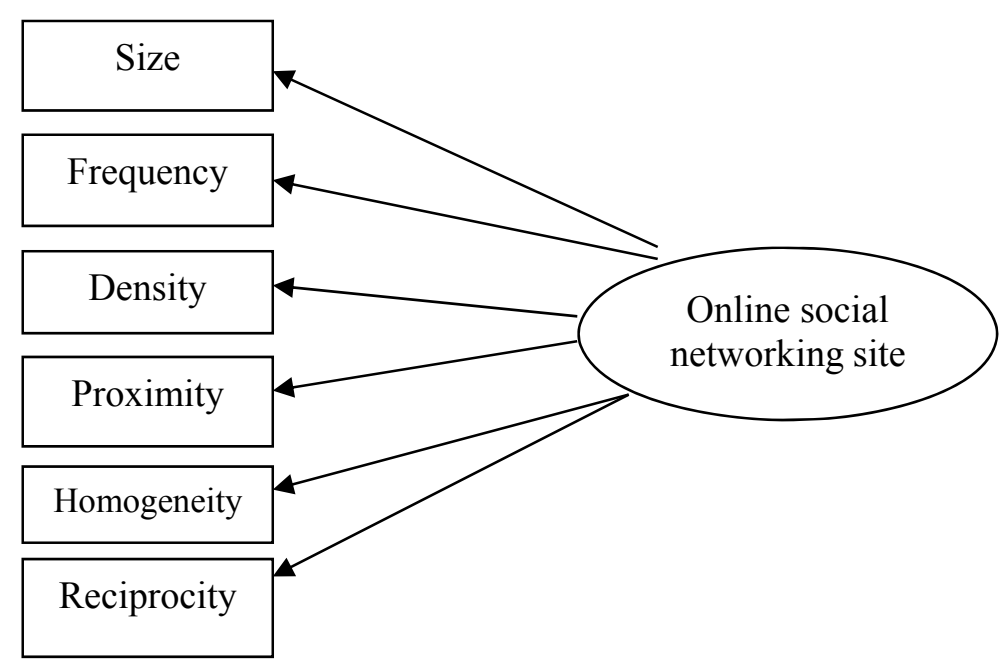

Fig. 1. Conceptual model of research:

\subsubsection{Research Variables}

According to Fig. 1, the primary variable of research is online social network and the secondary variables are the indexes series, which are for every structure in Table 2 to Table 7.

\subsection{Research propositions}

According to a literature review and the proposed conceptual model, the research questions can be stated as follows:

Primary question:

What is the framework of online social network features?

Secondary research questions are explained as follows:

- What are the main indicators of the size of online social networks?

- What are the main indicators of homogeneity of social network online?

- What are the main indicators of the frequency of online social networking?

- What are the main indicators of online social network density?

- What are the main indicators of online social networks nodes' proximity?

- What are the main indicators of support reciprocity of online social network?

\subsection{Research methodology}

In terms of objective, this survey is practical descriptive. The result of research can be used by senior managements, internet marketers and experts of creating online social networks. Instrument used in this research is a questionnaire on the base of Quintuplet Likret spectrum.

\subsection{Statistical society and Sample:}

Statistic society of research includes graduate students who have had the experiences of membership in online social network. Sampling is accomplished, randomly and electronic questionnaire has been sent to them via electronic post. According to Morgan Table, sample consists of 384 individuals.

\subsection{Validity and reliability of research}

To ensure the reliability of research questionnaire, the ideas of supervisors, consultants and experts were used and some necessary modifications were also applied. In addition, to analyze the 
determination and measuring each variable through related questions, we have used structural validity. In this research, to measure validity, we used Cronbach's Alpha. By using analyzing research data through statistical software SPSS, the coefficient Cronbach's Alpha of all questions have been determined. Therefore, it can be said that research questions have a desirable validity. For all variables of research, in final stage, the alpha is calculated which is confirmatory for all of them.

\section{Research results}

\subsection{Descriptive research results}

According to demographic information received from questionnaire. $40.3 \%$ of responsible were men and $55.5 \%$ were women. Responsible are divided into four groups according to their education where $36.5 \%$ of them hold BS degree, $62.8 \%$ of them maintained master and $7 \%$ of them had Ph.D. Data were collected about the place of access to the internet, the respondents were classified into three different groups. According to our survey, $84.6 \%$ of the participants had access to internet from their homes, $3.1 \%$ of them reached internet from their work and $12.3 \%$ of them from university. In addition, $40.6 \%$ of the participants were members of fewer than 2 networks, $58.1 \%$ of them were members of $2-4$ networks and $1.3 \%$ of them had membership in more than 4 networks.

\subsection{Statistical analysis}

Based on the information gathered, the amount of validity for each aspect is calculated separately and since all of them were higher than 0.7 , it can be possible to confirm the validity of research. Also the adequacy of sampling (KMO index) is confirmed.

\section{Table 7}

Statistical analysis of research model

\begin{tabular}{|c|c|c|c|c|c|c|}
\hline Aspect & Components & Factor loading & Result & t-value & Cronbach' Alpha & $\mathrm{KMO}$ \\
\hline \multirow{4}{*}{ Size } & Question1 & 0.74 & approval & 16.35 & \multirow{4}{*}{0.864} & \multirow{4}{*}{0.815} \\
\hline & Question2 & 0.78 & approval & 17.55 & & \\
\hline & Question3 & 0.76 & approval & 16.95 & & \\
\hline & Question4 & 0.85 & approval & 20.27 & & \\
\hline \multirow{4}{*}{ Homogeneity } & Question5 & 0.65 & approval & 13.65 & \multirow{4}{*}{0.831} & \multirow{4}{*}{0.804} \\
\hline & Question6 & 0.74 & approval & 16.19 & & \\
\hline & Question7 & 0.74 & approval & 16.22 & & \\
\hline & Question8 & 0.80 & approval & 18.33 & & \\
\hline \multirow{5}{*}{ Frequency } & Question9 & 0.72 & approval & 15.77 & \multirow{5}{*}{0.850} & \multirow{5}{*}{0.834} \\
\hline & Question10 & 0.72 & approval & 15.82 & & \\
\hline & Question11 & 0.77 & approval & 17.23 & & \\
\hline & Question12 & 0.67 & approval & 14.36 & & \\
\hline & Question13 & 0.71 & approval & 15.40 & & \\
\hline \multirow{3}{*}{ Density } & Question14 & 0.77 & approval & 17.03 & \multirow{3}{*}{0.837} & \multirow{3}{*}{0.788} \\
\hline & Question15 & 0.76 & approval & 16.65 & & \\
\hline & Question17 & 0.67 & approval & 14.26 & & \\
\hline \multirow{3}{*}{ Proximity } & Question 18 & 0.74 & approval & 16.07 & \multirow{3}{*}{0.816} & \multirow{3}{*}{0.718} \\
\hline & Question19 & 0.76 & approval & 16.70 & & \\
\hline & Question20 & 0.78 & approval & 17.38 & & \\
\hline \multirow{2}{*}{ Reciprocity } & Question21 & 0.80 & approval & 17.39 & \multirow{2}{*}{0.724} & \multirow{2}{*}{0.700} \\
\hline & Question22 & 0.69 & approval & 14.68 & & \\
\hline
\end{tabular}

According to the results of Table 7, it can be determined which indicators are more important. Also, with respect to different indexes of the model, it can be concluded that the conceptual model of the research has an appropriate fitting and the reliability of research structure will be confirmed.

\subsubsection{Confirmatory factorial analysis}

For analyzing the reliability of suggested variables in mentioned model the method of Confirmatory factorial analysis was used. Fig. 2 and Fig. 3 demonstrate the results of our investigation. 


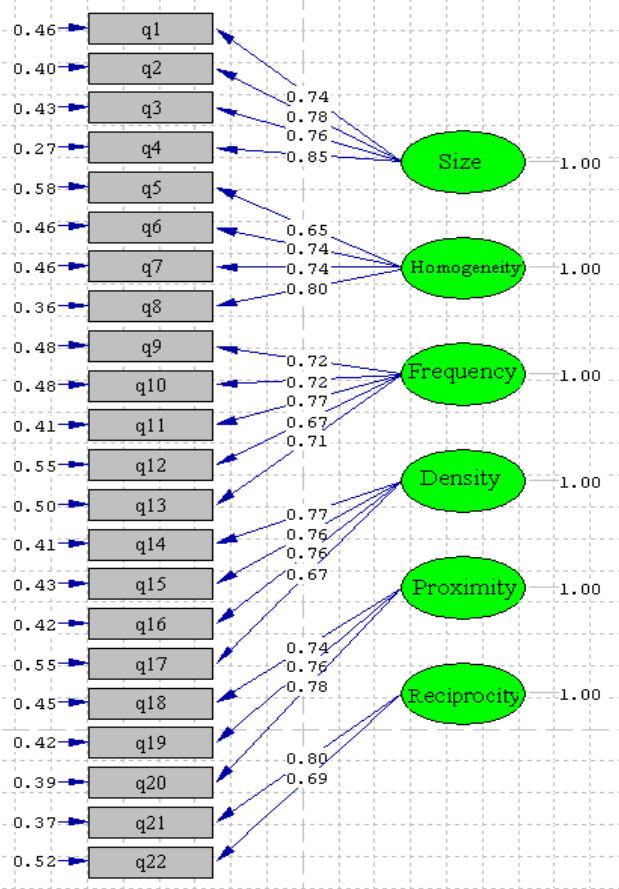

The results of standard coefficients

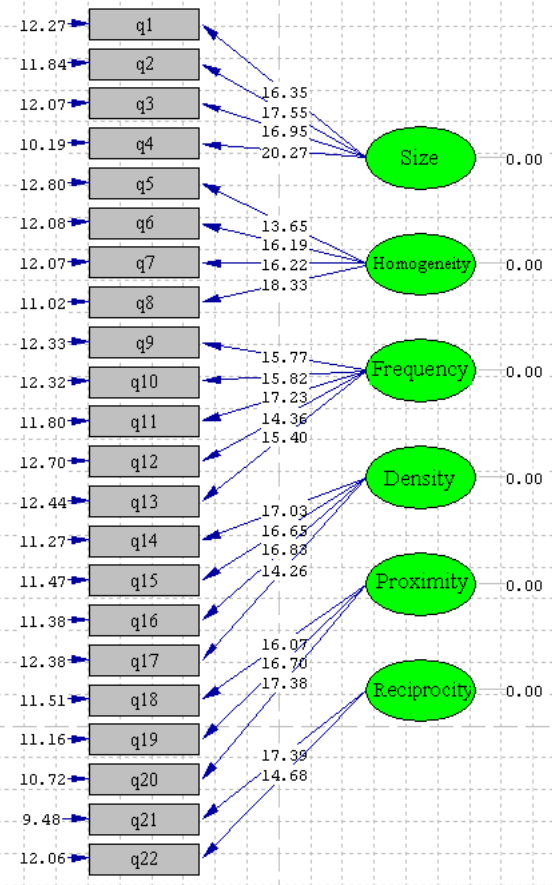

The results of t-values

Fig. 2. The results of first order standard coefficients and t-values

Table 8 shows details of Standard coefficients (Factor loading), explained variance and t-value of each of questions associated with variables of social network features. Factor loading of all questions has the necessary significance number (more than 1.96). So it can be suggested that all questions of variables of social network features have the necessary importance for measuring related variables.

\section{Table 8}

The summary of testing online social network features

\begin{tabular}{|c|c|c|c|c|}
\hline Variahle & auestion & t value & Fxnlained Variance & Standard coefficient \\
\hline \multirow{4}{*}{ Size } & Ouestion1 & 16.35 & 0.54 & 0.74 \\
\hline & Question2 & 17.55 & 0.60 & 0.78 \\
\hline & Question3 & 16.95 & 0.57 & 0.76 \\
\hline & Question4 & 20.27 & 0.72 & 0.85 \\
\hline \multirow{4}{*}{ Homogeneity } & Ouestion5 & 13.65 & 0.42 & 0.65 \\
\hline & Question6 & 16.19 & 0.54 & 0.74 \\
\hline & Question7 & 16.22 & 0.54 & 0.74 \\
\hline & Question8 & 18.33 & 0.64 & 0.80 \\
\hline \multirow{5}{*}{ Frequency } & Ouestion9 & 15.77 & 0.51 & 0.72 \\
\hline & Question10 & 15.82 & 0.51 & 0.72 \\
\hline & Question11 & 17.23 & 0.59 & 0.77 \\
\hline & Question12 & 14.36 & 0.44 & 0.67 \\
\hline & Question 13 & 15.40 & 0.50 & 0.71 \\
\hline \multirow{4}{*}{ Density } & Ouestion14 & 17.03 & 0.59 & 0.77 \\
\hline & Question15 & 16.65 & 0.57 & 0.76 \\
\hline & Question16 & 16.83 & 0.57 & 0.76 \\
\hline & Question17 & 14.26 & 0.44 & 0.67 \\
\hline \multirow{3}{*}{ Proximity } & Ouestion 18 & 16.07 & 0.54 & 0.74 \\
\hline & Question19 & 16.70 & 0.57 & 0.76 \\
\hline & Question20 & 17.38 & 0.60 & 0.78 \\
\hline \multirow{2}{*}{ reciprocity } & Question21 & 17.39 & 0.64 & 0.80 \\
\hline & Question 22 & 14.68 & 0.47 & 0.69 \\
\hline
\end{tabular}




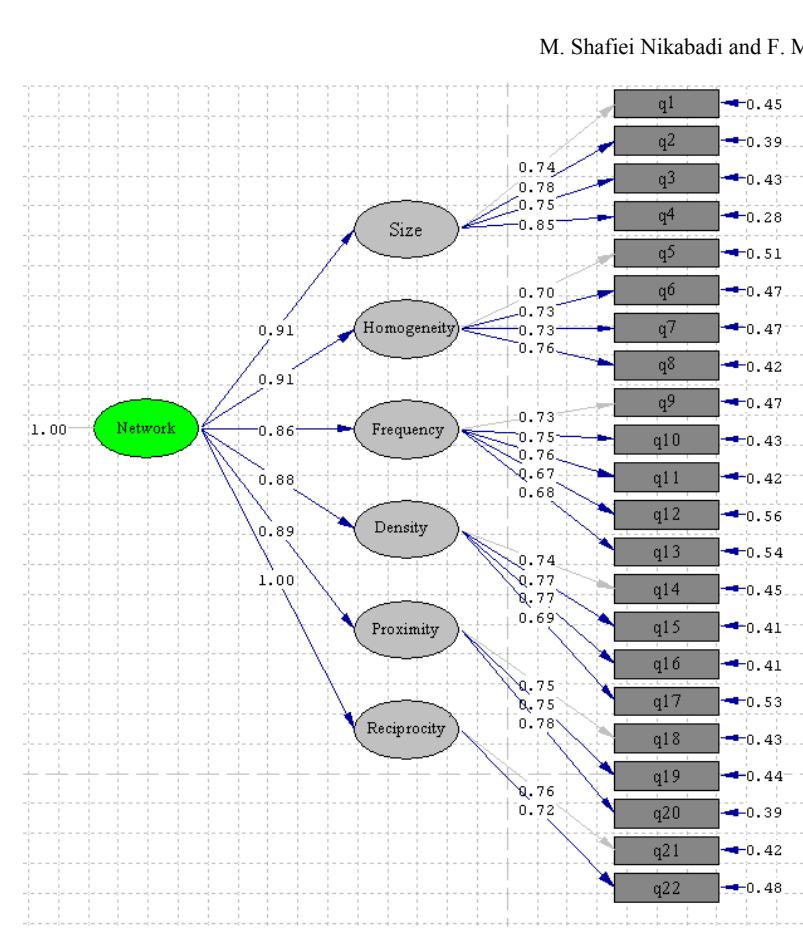

The results of standard coefficients

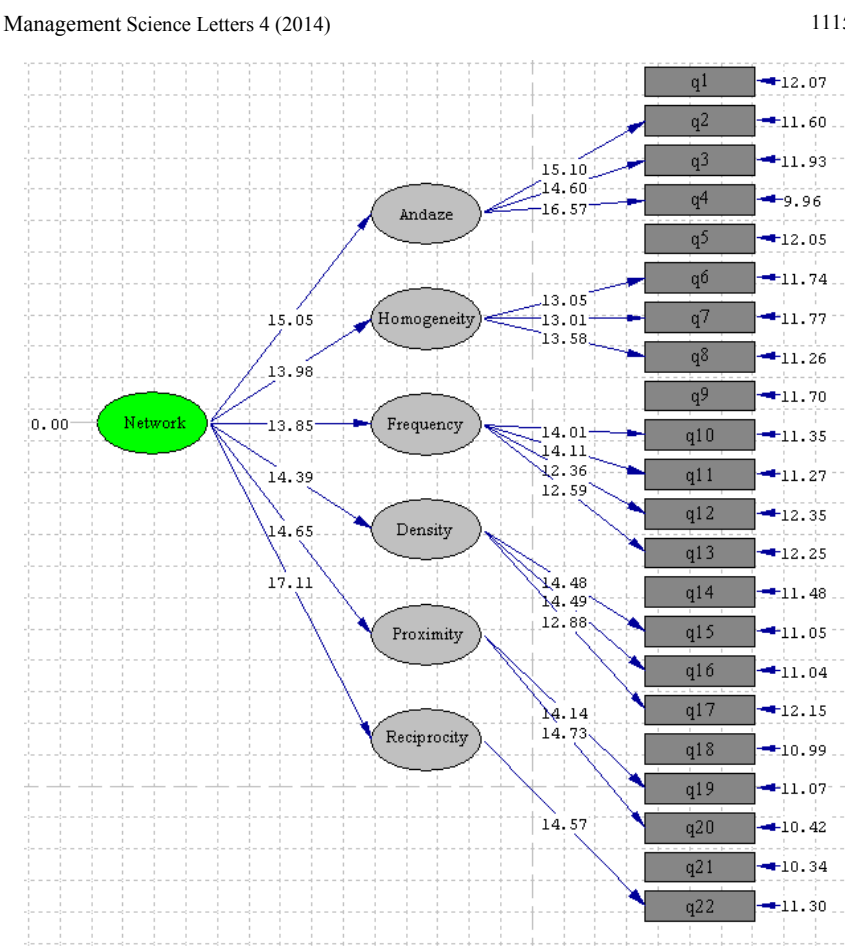

The results of t-values

Fig. 3. The results of second order confirmatory factor analysis model for the characteristics of online social networks

\section{Conclusions and recommendations}

During the research it has been determined that the framework possessed an appropriate reliability both with the respect of structure and recognition. In this framework, features of online social network were defined and they were analyzed thorough factor loading technic. According to our research results, in terms of size, the number of people who apply for membership in various online social networking is an important index. In terms of individual preference to connect with, people who are relative play essential role. In terms of homogeneity variable, the number of people who visit their friends' pages is important for measuring frequency variable. In terms of frequency, the use of entertainment and recreation services is more important index. In terms of proximity, being in the same city is a more important index and index of creating a sense of belonging and confidence is more important for measuring reciprocity variable.

In our survey, using personal social network and collecting information influence on the purchase behavior. Recommendation engines and products comparison sites help consumers recognize new products and evaluate them more detailed but cannot be considered as substitute for personal advice and information that people receive from their friends or relatives.

Studding and analyzing online social network in order to understand online social networks' workload and internet traffic for designing the foundations of the next internet generation and content distribution systems is a good future work. Understanding the interactions of users when connect to social network sites, provides the opportunities for designing better user relationship, richer studies of social interaction, designing and improving content distribution systems and we leave these issues for interested researchers as future studies.

\section{References}

Ashida, S. (2005). Social network characteristics and intention to participate in social activity programs at a new senior center (Doctoral dissertation, Ohio State University). 
Benevenuto, F., Rodrigues, T., Cha, M., \& Almeida, V. (2012). Characterizing user navigation and interactions in online social networks. Information Sciences, 195, 1-24.

Cheung, C. M., Chiu, P. Y., \& Lee, M. K. (2011). Online social networks: Why do students use facebook?. Computers in Human Behavior, 27(4), 1337-1343.

Cheung, C. M., \& Lee, M. K. (2010). A theoretical model of intentional social action in online social networks. Decision support systems, 49(1), 24-30.

Din, N., Yahya, S., Suzan, R., \& Kassim, R. (2012). Online social networking for quality of life. Procedia-Social and Behavioral Sciences, 35, 713-718.

Fu, F., Liu, L., \& Wang, L. (2008). Empirical analysis of online social networks in the age of Web 2.0. Physica A: Statistical Mechanics and its Applications, 387(2), 675-684.

Glass, T. A., de Leon, C. M., Marottoli, R. A., \& Berkman, L. F. (1999). Population based study of social and productive activities as predictors of survival among elderly Americans. BMJ: British Medical Journal, 319(7208), 478.

Hanneman, R. A., \& Riddle, M. (2005). Introduction to social network methods.

Heidemann, J., Klier, M., \& Probst, F. (2012). Online social networks: A survey of a global phenomenon. Computer Networks, 56(18), 3866-3878.

ten Kate, S., Haverkamp, S., Mahmood, F., \& Feldberg, F. (2010). Social network influences on technology acceptance: A matter of tie strength, centrality and density. BLED 2010 Proceedings, Paper, 40.

Katona, Z., Zubcsek, P. P., \& Sarvary, M. (2011). Network effects and personal influences: The diffusion of an online social network. Journal of Marketing Research, 48(3), 425-443.

Mergel, I., \& Langenberg, T. (2006). What makes online ties sustainable? A research design proposal to analyze online social networks. Harvard Program on networked governance.

Lee, C., Scherngell, T., \& Barber, M. J. (2011). Investigating an online social network using spatial interaction models. Social Networks, 33(2), 129-133.

Martins, M. E., Martins, G. S., Csillag, J. M., \& Pereira, S. C. F. (2012). Service's scientific community: a social network analysis (1995-2010). Journal of Service Management, 23(3), 455469.

Mayer, A. (2009). Online social networks in economics. Decision Support Systems, 47(3), 169-184.

Michaelidou, N., Siamagka, N. T., \& Christodoulides, G. (2011). Usage, barriers and measurement of social media marketing: An exploratory investigation of small and medium B2B brands. Industrial Marketing Management, 40(7), 1153-1159.

Mislove, A., Marcon, M., Gummadi, K. P., Druschel, P., \& Bhattacharjee, B. (2007, October). Measurement and analysis of online social networks. In Proceedings of the 7th ACM SIGCOMM conference on Internet measurement (pp. 29-42). ACM.

Pallis, G., Zeinalipour-Yazti, D., \& Dikaiakos, M. D. (2011). Online social networks: status and trends. In New Directions in Web Data Management 1 (pp. 213-234). Springer Berlin Heidelberg.

Shiau, W. L., \& Luo, M. M. (2012). Factors affecting online group buying intention and satisfaction: A social exchange theory perspective. Computers in Human Behavior, 28(6), 2431-2444.

Wang, X., Yu, C., \& Wei, Y. (2012). Social media peer communication and impacts on purchase intentions: A consumer socialization framework. Journal of Interactive Marketing, 26(4), 198-208.

Zhao, X., Yuan, J., Li, G., Chen, X., \& Li, Z. (2012). Relationship strength estimation for online social networks with the study on Facebook. Neurocomputing, 95, 89-97. 